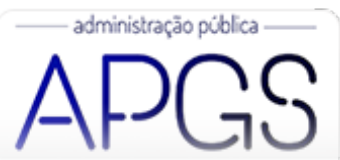

Administração Pública e Gestão Social ISSN: 2175-5787

apgs@ufv.br

Universidade Federal de Viçosa

Brasil

\title{
Financiamento, Composição dos Gastos e Eficiência na Saúde dos Municípios Pernambucanos
}

Morais de Sousa, Kleber; Santos Fornitani Pinhanez, Monica de Maria; Aguiar do Monte, Paulo; Nóbrega Cavalcante, Paulo Roberto

Financiamento, Composição dos Gastos e Eficiência na Saúde dos Municípios Pernambucanos Administração Pública e Gestão Social, vol. 12, núm. 3, 2020

Universidade Federal de Viçosa, Brasil

Disponible en: http://www.redalyc.org/articulo.oa?id=351563312006

Esta obra está bajo una Licencia Creative Commons Atribución-NoComercial-SinDerivar 3.0 Internacional. 


\title{
Financiamento, Composição dos Gastos e Eficiência na Saúde dos Municípios Pernambucanos
}

\author{
Financing, Expenditure Composition and Efficiency in the Healthcare System of Cities in Pernambuco - Brazil \\ Financiamiento, Composición de los Gastos y Eficiencia en la Salud de los Municipios Pernambucanos
}

Kleber Morais de Sousa

Universidade Federal Rural de Pernambuco, Brasil

Redalyc: http://www.redalyc.org/articulo.oa?

kleberfinancas@gmail.com

Monica de Maria Santos Fornitani Pinhanez

Instituto de Ensino e Pesquisa, Brasil

monicapinhanez@yahoo.com

Paulo Aguiar do Monte

Universidade Federal da Paraíba, Brasil

pauloaguiardomonte@gmail.com

Paulo Roberto Nóbrega Cavalcante

Universidade Federal da Paraíba, Brasil

paulocavalcante@ccsa.ufpb.br

\section{Resumo:}

Este trabalho teve por objetivo investigar a influência do financiamento e da composição do gasto público na eficiência da produção dos serviços de saúde dos municípios do estado de Pernambuco. A pesquisa foi realizada em dois estágios: O primeiro mensurou a eficiência e o segundo analisou a eficiência frente às variáveis financeiras e de controle por meio de regressão múltipla com dados em painel e efeitos fixos. A amostra do estudo foi formada pelos 184 municípios pernambucanos e os dados compreenderam o período de 2011 a 2015. Os resultados evidenciaram que a população com idade igual ou superior a 60 anos influencia negativamente na eficiência dos serviços de saúde dos municípios, enquanto o gasto com pessoal em saúde, o gasto com investimento em saúde, a despesa em saúde financiada com recursos do Sistema Único de Saúde (SUS) e a despesa em saúde financiada com recursos de impostos influenciam positivamente na eficiência.

Palavras-chave: Gestão em saúde, governos locais, eficiência, gasto público.

\section{Abstract:}

This paper investigates the effects of financing and public expenditure composition on the production of healthcare services in cities of Pernambuco, in the Northeast region of Brazil. The research was divided into two stages. During the first stage efficiency measurements were conducted while the second was dedicated to assess efficiency regarding both financial and control variables by means of multiple regression with panel data and fixed effects. The sample of the study was composed of 184 cities in the state of Pernambuco and data comprehends from 2011 to 2015. Results show that the population equal or higher than 60 years of age have a negative impact on the efficiency of healthcare services whereas expenses with health care professionals, investments and expenses financed with resources from the Brazilian Health Unic System (SUS) and tax collection are positive influences on efficiency.

KEYWORDS: Healthcare management, local governments, efficiency, public expenditure.

\section{Resumen:}

Esta investigación tuvo por objetivo examinar la influencia del financiamiento y de la composición del gasto público en la eficiencia de la producción de los servicios de salud de los municipios del Estado de Pernambuco, en Brasil. La averiguación se realizó en dos etapas. La primera etapa midió la eficiencia y la segunda analizó la eficiencia frente a las variables financieras y de control por medio 
de regresión múltiple con datos en panel y efectos fijos. La muestra del estudio fue formada por los 184 municipios pernambucanos y los datos comprendieron el período de 2011 a 2015. Los resultados evidenciaron que la población con edad igual o superior a 60 años influye negativamente en la eficiencia de los servicios de salud de los municipios, mientras que el gasto con personal en la salud, el gasto en inversión en salud, el gasto en salud financiada con recursos del Sistema Único de Salud (SUS) y el gasto en salud financiada con recursos fiscales influyen positivamente en la eficiencia.

Palabras Clave: Gestión de la salud, gobiernos locales, eficiencia, gasto público.

\section{INTRODUÇÃO}

Nas últimas décadas, a expansão dos direitos sociais provocou o crescimento do gasto público, tendo como principal fonte de financiamento o aumento da carga tributária que alcançou 36,4\% no ano de 2014 (World Bank, 2016). Nesse contexto, os governos locais ganharam maior participação na oferta de serviços públicos e o setor público de forma geral passou por iniciativas de reformas administrativas, tendo como propósito a modernização da administração pública e a melhoria do gasto público (Bresser-Pereira, 2000; Bresser-Pereira, 2009). Apesar disso, os níveis municipal, estadual e federal ainda carecem de melhor gestão na utilização de recursos, sendo a eficiência um tema de relevância.

A descentralização dos serviços públicos, ocorrida principalmente a partir de 1988, ampliou a participação dos governos municipais na realização dos gastos e na oferta dos serviços públicos, com a expectativa de democratizar a alocação dos recursos e de aumentar a eficiência. No setor de saúde não foi diferente, a partir da implementação do Sistema Único de Saúde (SUS) nos anos 1990, a descentralização dos serviços de saúde foi uma diretriz base, algo que tornou os municípios os principais provedores de serviços básicos de saúde no Brasil (Pinto, Soranz, Scardua, \& Silva, 2017).

Por outro lado, a universalização do acesso à saúde promovido pela Constituição Federal de 1988, sem destinar fontes de recursos estáveis e suficientes ao seu financiamento, gerou dificuldades financeiras nos governos locais. A solução parcial para insuficiência financeira foi buscada pela criação da obrigatoriedade de aplicação mínima de 15\% dos recursos resultantes de impostos em ações e serviços de saúde pela Emenda Constitucional $n^{\circ}$ 29/2000 e pela Lei Complementar no 141/2012. Entretanto, a regra de aplicação mínima acaba por obrigar o gestor a realizar gasto, mesmo que não tenha sido definida a melhor técnica e alocação, pois caso o gestor não cumpra, pode sofrer sanções criminais e o município pode ser impedido de receber transferências voluntárias (Santos, Mendes, Pereira, \& Paranhos, 2017).

Além desse limite mínimo de gasto em saúde, nas últimas décadas, regras fiscais foram incrementadas com a definição de prioridades no uso dos recursos e para estabelecer controle dos gastos e do endividamento, por exemplo: (a) Aplicação mínima de $25 \%$ dos recursos resultantes de impostos em educação; (b) Limite máximo de $54 \%$ da receita corrente líquida em despesas com pessoal do Poder Executivo; (c) Aplicação mínima de 60\% das receitas do Fundo de Manutenção e Desenvolvimento da Educação Básica e de Valorização dos Profissionais da Educação (FUNDEB) na remuneração dos profissionais do magistério, e (d) Limite máximo de $120 \%$ da receita corrente líquida para a dívida fundada líquida. Assim, como se pode notar, por um lado, o gestor público necessita realizar gastos para cumprimento das regras de aplicações mínimas, por outro, é obrigado a reduzir despesas para não provocar gasto e endividamento excessivos. Em outras palavras, as normas fiscais não levam em consideração a eficiência do gasto, por apenas definir prioridades e limites de aplicação (Pacheco, Abrantes, Zuccolotto, Luquini, 2017).

Este trabalho busca contribuir justamente em identificar aspectos financeiros que influenciam na eficiência da produção dos serviços de saúde dos governos locais. Compreende-se por eficiência, para fins deste estudo, a capacidade de utilizar a menor quantidade de recursos financeiros possível, mantendo ou acrescendo a quantidade dos bens públicos produzidos (Achabal, Heineke, \& Mcjntyre, 1984; Ken, Chu, \& Xu, 2006; Asmild, Paradi, Reese, \& Tam, 2007; Varabyova \& Müller, 2016; Cetin \& Bahce, 2016; Carrillo \& Jorge, 2017; Herwartz \& Schley, 2018; Ibrahim, Daneshvar, Hocaoğlu, \& Oluseye, 2018). Os resultados obtidos 
podem auxiliar principalmente no aprimoramento das regras fiscais e na melhoria da qualidade do gasto público.

Assim, o estudo teve por objetivo investigar a influência do financiamento e da composição do gasto público na eficiência da produção dos serviços de saúde dos municípios do estado de Pernambuco. Para tanto, a pesquisa utilizou métodos quantitativos em dois estágios. No primeiro estágio foi mensurada a eficiência da produção dos serviços de saúde dos municípios, por meio da análise de fronteira estocástica, e no segundo estágio, o indicador de eficiência apurado no primeiro estágio foi utilizado como variável dependente de uma regressão múltipla com as variáveis financeiras e de controle para verificação dos seus efeitos.

A amostra foi formada pelos 184 municípios do Estado de Pernambuco e o período compreendeu os anos de 2011 a 2015. Os dados foram coletados nas bases de dados de informações de saúde (Tabnet) e do Sistema de Informações sobre Orçamentos Públicos em Saúde (SIOPS) do Ministério da Saúde e nos censos do Instituto Brasileiro de Geografia e Estatística (IBGE).

Além dessa introdução, o estudo está dividido em mais cinco partes. A segunda parte trata do referencial teórico relacionado a eficiência, financiamento e composição do gasto no setor de saúde dos municípios. A terceira parte evidencia a metodologia, detalhando as variáveis e os modelos utilizados. A quarta parte apresenta os resultados descritivos e inferenciais e a quinta apresenta as discussóes relacionadas ao tema e aos resultados obtidos. Ao final, na sexta parte, são apresentadas as conclusões do estudo.

\section{REFERENCIAL TEÓRICO}

\subsection{Eficiência do Gasto Público}

A ampliação do gasto público local e a transferência de responsabilidade da produção dos serviços públicos para os governos municipais tiveram como propósito a maior democratização, a melhoria da eficiência e a ampliação do controle social da aplicação dos recursos públicos, visto que, quanto mais próximo o gasto estiver do cidadão, melhor será a avaliação e alocação dos recursos frente às necessidades e peculiaridades existentes (Oates, 1999; Afonso \& Araújo, 2000; Rodden, 2003; Kis-Katos \& Sjahrir, 2017).

Contudo, a descentralização por si só não garante que a eficiência do gasto seja alcançada, pois a decisão de escolha do gasto público ocorre em mais de cinco mil municípios brasileiros, o que implica em maiores dificuldades administrativas no seu controle, seja na observância de preceitos normativos ou no alcance das metas e dos objetivos. Além disso, a autonomia administrativa, política e financeira assegurada constitucionalmente aos municípios brasileiros pode resultar em excessos e desperdícios, com o propósito de atender aos interesses de elites políticas e econômicas (Abrúcio, 2006). Por outro lado, a preocupação com eficiência tem sido resultado das dificuldades financeiras dos governos que não possuem mais condições de realizar aumento na receita corrente por meio da tributação para atender a crescente ampliação do gasto público (Barton, 2009).

Neste estudo, eficiência é a otimização do uso dos recursos financeiros do ente público, ou seja, produzir mais com a menor quantidade possível de recursos financeiros (Achabal, Heineke, \& Mcjntyre, 1984; Ken, Chu, \& Xu, 2006; Asmild et al., 2007; Varabyova \& Müller, 2016; Cetin \& Bahce, 2016; Carrillo \& Jorge, 2017; Herwartz \& Schley, 2018; Ibrahim et al., 2018). Os estudos sobre eficiência tiveram início em 1957 com o trabalho de Farrell (1957). Na área da saúde foi produzida expressiva quantidade de artigos no cenário internacional. Um levantamento realizado por Hollingsworth (2008) apontou que durante o ano de 1983 até meados do ano de 2006 foram publicados 317 artigos em periódicos internacionais. No Brasil foram poucas as pesquisas desenvolvidas, sendo destaques as realizadas por Marinho (1998); Marinho e Façanha (2000); Marinho (2003); Ferreira e Pitta (2008); Varela (2008); Fonseca e Ferreira (2009); Varela, Martins e Fávero (2010); Varela, Martins e Fávero (2012); Queiroz, Silva, Figueiredo e Vale (2013); Mazon, Mascarenhas e 
Dallabrida (2015); Braga, Ferreira e Braga (2015); Costa, Ferreira, Braga e Abrantes (2015) e Portulhak, Raffaelli e Scarpin (2018). A literatura sobre eficiência tem apontado que fatores econômicos (Greene, 2010; Afonso \& Aubyn, 2011; Hadad, Hadad, \& Simon-Tuval, 2013; Fonchamnyo \& Sama, 2016), sociais (PuigJunoy, 1998; Kumbhakar, 2010) e demográficos (Afonso \& Aubyn, 2005; Afonso \& Aubyn, 2011; Allin, Grignon, \& Wang, 2016) são responsáveis por níveis diferenciados de eficiência em atenção primária de saúde. Contudo, pouca atenção tem sido dispensada aos aspectos financeiros, em especial nos governos locais.

No Brasil, a política fiscal adotada nos últimos vinte anos estabeleceu normas que definem limites mínimos e máximos dos gastos públicos e do endividamento dos municípios, como meio de restringir o uso dos recursos públicos, de priorizar áreas especificas de atuação e de afastar interesses individuais oportunistas, como aponta a teoria da escolha pública (Downs, 1957; Buchanan \& Tullock, 1962).

As principais restrições fiscais dos municípios brasileiros são: Limite máximo de $54 \%$ da Receita Corrente Líquida (RCL) com gastos com pessoal do poder executivo (LC 101/2000), aplicação mínima de recursos resultantes de impostos em áreas de saúde com 15\% (EC 29) e em educação com 25\%, aplicação mínima de $60 \%$ dos recursos do FUNDEB na remuneração dos profissionais do magistério, limite máximo de saldo financeiro do FUNDEB de $5 \%$ da receita anual do fundo e limite máximo de $120 \%$ da receita corrente líquida para a dívida fundada (Santos et al., 2017).

Embora pesquisas como as realizadas por Sacramento (2005); Fioravante, Pinheiro e Vieira (2006); Macedo e Corbari (2009); Santolin, Jayme e Reis (2009) e Gerigk, Clemente e Taffarel (2010) tenham apontado evidências positivas das imposições legais, em especial do gasto com pessoal da Lei de Responsabilidade Fiscal (LRF), a relação desses limites com a eficiência do gasto público, como proposto neste estudo, não tem sido pesquisada. Ou seja, os limites fiscais, especificamente aqueles relacionados a aplicações mínimas, podem resultar em gastos ineficientes, pois o gestor é obrigado a gastar o recurso público em determinado exercício, mesmo não tendo definido a forma técnica e alocativa mais adequada.

\subsection{Financiamento, Composição do Gasto e Eficiência em Saúde nos Municípios}

O SUS foi instituído com o intuito de unificar as instituições prestadores de serviços públicos de saúde das três esferas de governo em um único sistema, baseado nas diretrizes de descentralização, atendimento integral e participação popular (Fontoura \& Mayer, 2006). Nesse sentido, em meados dos anos 1990, os governos subnacionais passaram a ser os principais provedores dos serviços públicos de saúde, sendo as transferências de recursos do governo federal uma ferramenta importante para redução da disputa pelos recursos federais (Souza, 2005; Paim, Travassos, Almeida, Bahia, \& Macinko, 2011).

$\mathrm{Na}$ distribuição de atribuições, a União ficou responsável pela coordenação das atividades intergovernamentais, do financiamento e da formulação da política nacional (Arretche, 2004). As transferências do SUS definidas por critérios populacionais e pela produção têm custeado cerca da metade das despesas com saúde realizadas nos municípios. Essas transferências, na maioria das vezes, são condicionadas à implementação de programas como, por exemplo, o Programa de Saúde da Família (PSF) e o Programa de Agentes Comunitários de Saúde (PACS) (Melamed \& Costa, 2003; Scatena, Viana, \& Tanaka, 2009; Simão \& Orellano, 2015).

Contudo, a descentralização financeira por meio de transferências automáticas para os governos locais não foi suficiente para assegurar os recursos necessários ao atendimento da demanda pelos serviços. A substituição de um modelo assistencial baseado no princípio contributivo e centralizado por um universal, hierarquizado e descentralizado como o SUS (Arretche, 2003) ocorreu sem que fossem definidas fontes de financiamentos estáveis para o sistema, de modo que o volume de recursos destinados à saúde permaneceu o mesmo (Fleury, 2009).

Os esforços de prover o SUS com fontes estáveis resultaram na edição da Emenda Constitucional no 29 (EC 29) e mais recentemente na Lei Complementar no 14/2012, que obriga a aplicação mínima de 15\% 
dos recursos arrecadados resultantes de impostos nas ações e serviços de saúde nos municípios. Todavia, esse critério não considera a fragilidade fiscal dos municípios brasileiros, que em muitos casos possuem baixa capacidade de arrecadação de impostos para o financiamento da área de saúde (Dain, 2007). A rede assistencial reproduz essa desigualdade de arrecadação, onde as regiões menos favorecidas estão sempre defasadas em relação aos mais desenvolvidos (Fleury, Ouverney, Möller, Kronemberger, \& Zani, 2014).

Portanto, a transferência de recursos do SUS e a garantia de aplicação mínima dos recursos arrecadados resultantes de impostos parecem não ter sido suficientes para assegurar a prestação de serviços uniforme dentre os municípios, já que existem outros fatores que influenciam, como, por exemplo, as desigualdades sociais e demográficas. Além disso, os inúmeros instrumentos normativos utilizados pelo Ministério da Saúde para disciplinar a aplicação dos recursos não têm conseguido assegurar um padrão mínimo de eficiência para o gasto público em saúde dos municípios brasileiros (Wagner, 2006; Faria, Nascimento, Farias, \& Nunes, 2017).

Do ponto de vista da eficiência, a composição dos gastos públicos por natureza econômica é um elemento importante, porque gastos relacionados a pessoal e a investimentos podem afetar na alocação e técnica de produção dos serviços. Os gastos com pessoal no âmbito local sempre foram vistos como atrelados a interesses políticos, onde critérios técnicos não são levados em consideração, afetando a eficiência do gasto público (Carvalho, 2002). A LRF cuidou de limitar esses gastos em 54\% da Receita Corrente Líquida para o poder executivo, entretanto, o critério utilizado não leva em consideração a necessidade de utilização de mão-deobra intensiva em determinados setores, de modo que a restrição pode comprometer a eficiência do gasto (Luque \& Silva, 2004; Medeiros, Albuquerque, Tavares, \& Souza, 2017).

No mais, a ampliação das despesas de caráter continuado é dificultada pela LRF com a exigência de apresentação de avaliação de impacto orçamentário e financeiro para os dois anos seguintes. Essa restrição existe com o propósito de assegurar a capacidade de investimento do ente público. Os gastos em investimentos são comumente vistos como elementos positivos, visto que sua realização amplia a capacidade de produção dos serviços, seja pela ampliação física ou pela renovação tecnológica. Desse modo, espera-se que os gastos com investimentos resultem em maior eficiência da máquina pública (Santolin et al., 2009; Gerigk et al., 2010).

\section{METODOLOGIA}

Os aspectos metodológicos foram desenvolvidos em dois estágios, tendo como base os trabalhos de Kumbhakar (2010), Oglobin (2011) e Hadad, Hadad e Simon-Tuval (2013). O primeiro estágio do método mensurou a eficiência produtiva dos sistemas de saúde dos municípios e o segundo estágio tratou de analisar a eficiência frente às variáveis financeiras e de controle por meio de regressão múltipla com dados em painel.

A mensuração da eficiência dos serviços de saúde foi realizada com base na análise de fronteira estocástica introduzida por Aigner, Lovell e Schmidt (1977) e Meeusen e Van Den Broeck (1977) e aperfeiçoado por Battese e Coelli (1992) e Kumbhakar e Lovell (2000). Esse método foi escolhido principalmente porque possui a capacidade de considerar erros aleatórios e de mensuração. A função de produção foi definida como uma função linear dos fatores de produção, tais como bens e serviços utilizados na produção, acrescido de dois elementos: it $_{\text {it }}$ representa o erro padrão que captura o efeito da ineficiência técnica da produção e ${ }_{\text {it }}$ representa o erro sistêmico que captura os choques aleatórios incontroláveis. A equação 1 define modelo utilizado:

$$
y_{i t}=\beta_{0}+\sum_{j=1}^{k} \beta_{j} x_{i t}+v_{i t}-s u_{i t}
$$

Onde i representa as unidades de produção e t representa os períodos; 
$\mathrm{y}_{\text {it }}$ denota a produção realizada pela unidade i no período t;

$\mathrm{B}_{0}$ denota a constante do modelo;

$\mathrm{B}_{\mathrm{j}}$ denota o coeficiente angular da variável $\mathrm{j}$;

$\mathrm{x}_{\mathrm{jit}}$ denota a variável $\mathrm{j}$ no período $\mathrm{t}$ relativo a unidade $\mathrm{i}$;

$\mathrm{v}_{\text {it }}$ denota o erro sistêmico da unidade i no período $t$;

$s$ denota o modo da função, 1 para função de produção e -1 para função de custo;

$\mathrm{u}_{\mathrm{it}}$ denota a ineficiência técnica da unidade i no período $t$.

O termo $\cdot$ it no modelo variável no tempo utilizado possui a seguinte especificação:

$$
u_{i t}=\exp \left\{-\eta\left(t-T_{i}\right)\right\} u_{i}
$$

Onde, $\mathrm{T}_{\mathrm{i}}$ é o último período no enésimo painel;

$\eta$ é o parâmetro de decréscimo do tempo.

O índice de eficiência da produção é obtido pela $\mathrm{e}^{\text {-uit }}$, que varia entre 0 (ineficiência total) e 1 (eficiência total). A amostra do estudo foi formada pelos 184 municípios do estado de Pernambuco e os dados compreenderam o período de 2011 a 2015. Os dados foram coletados nas bases de dados do Tabnet e do Sistema de Informações sobre Orçamentos Públicos em Saúde (SIOPS) do Ministério da Saúde e no censo do IBGE. As variáveis monetárias foram deflacionadas ao início da série (2011) com o Índice Nacional de Preços ao Consumidor (INPC) do IBGE. As variáveis utilizadas estão descritas no Quadro 1.

Quadro 1 - Descrição das Variáveis Utilizadas do Setor de Saúde dos Municípios Pernambucanos.

\begin{tabular}{|l|c|}
\hline \multicolumn{1}{|c|}{ Denominação/Definição } & Fonte \\
\hline $\begin{array}{l}\text { Denominação: Produção em Saúde (ln_produção) } \\
\text { Definição: Quantidade de atendimentos em ambulatório, internação (por local de internação) e no } \\
\text { Programa de Saúde da Família (PSF). }\end{array}$ & Tabnet \\
\hline $\begin{array}{l}\text { Denominação: Despesa Corrente (ln_despesacorrente) } \\
\text { Definição: Despesa com recursos humanos, materiais e serviços em ações de saúde. O valor foi obtido } \\
\text { pela subtração das despesas de capital em saúde da despesa registrada na função orçamentária 10 - } \\
\text { Saúde. }\end{array}$ & SIOPS \\
\hline $\begin{array}{l}\text { Denominação: Estrutura Física (ln_estrutura) } \\
\text { Definição: Quantidade de consultórios ambulatoriais e de leitos de internação mantidos no município. } \\
\text { Proxy da estrutura física utilizada na produção dos serviços de saúde. }\end{array}$ & Tabnet \\
\hline $\begin{array}{l}\text { Denominação: População (ln_pop) } \\
\text { Definição: Quantidade de pessoas residentes no município de acordo com estimativa do IBGE. }\end{array}$ & IBGE \\
\hline $\begin{array}{l}\text { Denominação: População com idade igual ou superior a 60 anos ln(populaçãosuperior60anos) } \\
\text { Definição: População com idade igual ou superior a 60 anos residente no município. }\end{array}$ & IBGE \\
\hline $\begin{array}{l}\text { Denominação: Médicos por mil habitantes } \\
\text { (ln medicopormilhabitantes) } \\
\text { Definição: Quantidade média de médicos anual dividida pela quantidade de habitantes (em milhares) } \\
\text { residentes no município. }\end{array}$ & Tabnet \\
\hline $\begin{array}{l}\text { Denominação: Gasto com pessoal em saúde (\%gastopessoalemsaude) } \\
\text { Definição: Percentual médio da despesa de pessoal em relação à despesa total de saúde do município. }\end{array}$ & SIOPS \\
\hline $\begin{array}{l}\text { Gasto com investimento em saúde (\%gastoinvestimentoemsaude) } \\
\text { Definição: Percentual médio da despesa com em investimento em relação à despesa total de saúde do } \\
\text { municipio. }\end{array}$ & SIOPS \\
\hline $\begin{array}{l}\text { Denominação: Gasto em saúde financiada com recursos do SUS (\%recursosus/despesatotalsaude) } \\
\text { Definição: Percentual dos gastos de saúde custeados com recursos do SUS. }\end{array}$ & SIOPS \\
\hline $\begin{array}{l}\text { Denominação: Gasto em saúde financiado com recursos resultantes de impostos } \\
\text { (\%recursoimposto/despesatotalsaude) } \\
\text { Definição: Percentual dos gastos de saúde custeados com recursos de impostos conforme estabelece a } \\
\text { Emenda Constitucional no 29/2000. }\end{array}$ & SIOPS \\
\hline
\end{tabular}


Apesar de os dados terem sido analisados com cautela antes da estimação, a pesquisa apresenta limitações em relação à fragilidade da base de dados do Departamento de Informática do Sistema Único de Saúde do Brasil(DATASUS), especificamente da atenção básica, porque os municípios ainda não mantêm uma correta alimentação do sistema (Santos, Pereira, \& Silveira, 2017). Outra limitação corresponde à utilização da quantidade de consultórios e de leitos de internamento como proxy da estrutura física, uma vez que a avaliação da estrutura física compreende aspectos qualitativos e quantitativos não contemplados na quantidade de ambulatórios e leitos disponíveis. Todavia, na falta de indicador que melhor represente a estrutura física, a proxy utilizada foi a melhor alternativa.

No primeiro estágio, a mensuração da eficiência foi realizada com as variáveis no modelo em formato $\log$ natural, conforme descrito na equação 3 :

$$
\ln (\text { produção })_{i t}=\beta_{0}+\beta_{1} \ln (\text { despesacorrente })_{i t}+\beta_{2} \ln (\text { estrutura })_{i t}+v_{i t}+s u_{i t}
$$

A utilização do modelo de função linear de produção com a determinação de fronteira estocástica teve por base os estudos realizados por Grossman (1972), Hollingsworth e Wildman (2003), Greene (2004), Afonso e Aubyn (2005) e Kumbhakar (2010). A escolha das variáveis $\ln$ (despesacorrente) e $\ln ($ estrutura) ocorreu por estas representarem os principais fatores de produção utilizados no processo produtivo dos serviços de saúde e tiveram por base os estudos de Marinho (2003), Ozcan (2008, 2009), e Park, Fowler e Giebel (2011). A variável $\ln$ (despesacorrente) é uma proxy dos recursos humanos e materiais e a variável $\ln$ (estrutura) é uma proxy dos equipamentos e da infraestrutura utilizada na produção dos serviços de saúde nos municípios pernambucanos. No mais, é importante destacar que a quantidade de internações utilizadas na produção dos serviços teve por base o local de atendimento, visto que a mensuração da eficiência busca avaliar a capacidade de produzir serviços em relação aos recursos utilizados em cada município. Portanto, não há interferência de pessoas que buscam atendimento de um município em outro.

No segundo estágio, o índice de eficiência de produção obtido para cada município e ano pela equação 3 foi regredido contra as variáveis exploratórias por meio da regressão múltipla com dados em painel, efeitos fixos e resíduos autoregressivos definida pela equação 4 :

$$
\begin{aligned}
\ln (\text { eficiência })_{\text {it }}= & \beta_{0}+\beta_{1} \ln (\text { populaçãosuperior60anos })_{\text {it }}+\beta_{2} \ln \left({\text { medicopormilhabitantes })_{i t}+}+\right. \\
& \beta_{3} \% \text { gastopessoalemsaude } \\
& \beta_{5} \% \text { recursosus } / \text { despesatotalsaude }{ }_{i t}+ \\
& \beta_{6} \% \text { recursoimposto/despesatotalsaude } \\
\text { it } & +\alpha_{i t}+u_{i t}
\end{aligned}
$$

As variáveis do modelo da equação 4 foram escolhidas pelos seguintes motivos:

1. Controlar o efeito demográfico da população com idade igual ou superior a 60 anos (Afonso \& Aubyn, 2005; Afonso \& Aubyn, 2011; Allin, Grignon, \& Wang, 2016);

2. Controlar a qualidade dos serviços de saúde oferecidos à população com a variável "médicos por mil habitantes" (Amado \& Dyson, 2008; Ferrera, Cebada, \& Zamorano, 2014)

3. Verificar se as maiores proporções dos gastos com pessoal provocam menor eficiência aos sistemas (Carvalho, 2002);

4. Analisar se os gastos com investimento aumentam a eficiência em razão do aperfeiçoamento da capacidade produtiva e do aprimoramento tecnológico (Santolin et al., 2009; Gerigk et al., 2010);

5. Verificar se a maior participação do financiamento do SUS resulta em maior eficiência, visto que esses recursos são disciplinados por normas definidas pelo Ministério da Saúde (Melamed \& Costa, 2003; Wagner, 2006; Scatena et al., 2009); 
6. Observar se a destinação de recursos próprios de impostos afeta de forma negativa, visto que esses recursos possuem menor regulamentação que os recursos do SUS e pela obrigatoriedade de cumprimento de aplicações mínimas no exercício (Bird, Freund, \& Wallich, 1995; Arretche, 2003; Dain, 2007).

\section{RESULTADOS}

\subsection{Resultados Descritivos}

Os municípios das macrorregióes pernambucanas apresentam perfil de estrutura física, despesa em saúde e de produção dos serviços de saúde bastante heterogêneos. Neste estudo, o estado de Pernambuco é tratado em quatro macrorregiões: Região Metropolitana (RM), com 14 municípios; Zona da Mata (ZM), com 43 municípios; Agreste (AG), com 71 municípios, e Sertão (ST), com 56 municípios. A Região Metropolitana está localizada no litoral, possui a maior densidade populacional do estado (1.383,64 habitantes $/ \mathrm{km}$.), desenvolve atividades econômicas diversificadas com produto interno bruto (PIB) per capita de $\mathrm{R} \$ 24.140,81$, segundo dados de 2015, e clima quente e úmido. Logo após a região metropolitana, a Zona da Mata possui densidade populacional de 152,55 habitantes $/ \mathrm{km}$., PIB per capita de $\mathrm{R} \$ 10.685,67$, clima tropical e média pluviométrica anual entre $1.500 \mathrm{~mm}$ e $2.000 \mathrm{~mm}$. Entre a Zona da Mata e o Sertão está localizado o Agreste, que possui densidade demográfica de 97,3 habitantes $/ \mathrm{km}$., PIB per capita de $\mathrm{R}$ $\$ 8.259,26$, clima semiárido e média pluviométrica anual entre $500 \mathrm{~mm}$ e $900 \mathrm{~mm}$. Por último, o Sertão possui a menor densidade demográfica (27,76 habitantes $/ \mathrm{km}$.), PIB per capita de $\mathrm{R} \$ 8.234,00$, clima quente e seco e a menor média pluviométrica anual, entre $400 \mathrm{~mm}$ e $600 \mathrm{~mm}$, distribuída irregularmente durante o ano (IBGE, 2018).

Os sistemas de saúde dos municípios pernambucanos também são diferentes. A Tabela 1 apresenta as estatísticas descritivas das variáveis "produção em saúde" (somatório da quantidade de atendimentos ambulatoriais, internações e atendimento em saúde da família), "despesa corrente" (despesa com recursos humanos, materiais e serviços em ações de saúde) e "estrutura física" (quantidade de consultórios e leitos) dos municípios por macrorregião. A análise descritiva demonstra as diferentes características regionais existentes no estado, entretanto, possui limitações relacionadas principalmente à identificação de idiossincrasias e a comparação com estudos paralelos que não utilizam esse recorte.

Tabela 1 - Estatísticas descritivas da produção em saúde, da despesa corrente e da estrutura física dos municípios pernambucanos, por macrorregião de Pernambuco, em R \$* 2011 a 2015

\begin{tabular}{|c|c|c|c|}
\hline \multirow[t]{2}{*}{ Macrorregiões* } & $\begin{array}{c}\text { Produção em } \\
\text { Saúde }\end{array}$ & $\begin{array}{l}\text { Despesa } \\
\text { Corrente }\end{array}$ & $\begin{array}{c}\text { Estrutura } \\
\text { Física }\end{array}$ \\
\hline & $\begin{array}{l}\text { Média/ } \\
\text { Desvio- } \\
\text { Padrão }\end{array}$ & $\begin{array}{c}\text { Média/ } \\
\text { Desvio-Padrão }\end{array}$ & $\begin{array}{c}\text { Média/ } \\
\text { Desvio- } \\
\text { Padrão }\end{array}$ \\
\hline \multirow[t]{2}{*}{$\mathrm{RM}$} & 4.087 .410 & 96.127 .948 & 118,10 \\
\hline & $(4.481 .624)$ & (163.084.992) & $(145,31)$ \\
\hline \multirow[t]{2}{*}{$\mathrm{ZM}$} & 753.823 & 9.692 .045 & 33,14 \\
\hline & (611.290) & $(7.045 .927)$ & $(21,42)$ \\
\hline \multirow[t]{2}{*}{$\mathrm{AG}$} & 780.950 & 9.542 .620 & 33,59 \\
\hline & $(1.032 .623)$ & $(1.263 .429)$ & $(32,34)$ \\
\hline \multirow[t]{2}{*}{ ST } & 698.799 & 8.979 .127 & 29,83 \\
\hline & (881.590) & (11.914.064) & $(24,50)$ \\
\hline
\end{tabular}

Desvio-padrão entre parênteses; *RM: Região Metropolitana; ZM: Zona da Mata; AG: Agreste; ST: Sertão. ${ }^{* *}$ Os valores monetários foram deflacionados a preços de 2011 pelo INPC/IBGE. 
A Região Metropolitana apresenta municípios com diferença populacional expressiva em relação aos municípios das demais macrorregióes do estado, uma vez que a Região Metropolitana possui a maior densidade populacional. Já em relação ao gasto médio, a Zona da Mata apresenta gasto superior ao Agreste ( $\mathrm{R}$ \$9.692.045,00 e $\mathrm{R} \$ 9.542 .620,00)$, enquanto, a quantidade média produzida pela primeira macrorregião, que gastou mais, é inferior a segunda, com 753.823 e 780.950, respectivamente.

A comparação entre os municípios das macrorregiões do Agreste e do Sertão evidencia que a produção, o gasto médio e a estrutura física são um pouco maiores na macrorregião Agreste. A média de gasto dos municípios das quatro macrorregiões é decrescente, quando observados os valores partindo do centro (Região Metropolitana) para a periferia (Sertão), acompanhando o grau de desenvolvimento econômico do estado. Entretanto, a comparação da produção de saúde e da despesa em termos per capita permite observar as diferenças sem o efeito do tamanho populacional, conforme apresentado na Tabela 2.

A produção ambulatorial e hospitalar per capita sugere que o acesso é maior nos municípios da macrorregião Sertão com 29,43, enquanto os municípios da macrorregião Metropolitana apresentam menor quantidade, com 20,43 procedimentos per capita. Os municípios da macrorregião Zona da Mata possuem 26,89 procedimentos per capita, número bastante semelhante aos municípios do Agreste, com 26,19 procedimentos per capita durante o período. Esses resultados contrariam a expectativa, já que a Região Metropolitana possui melhores condiçóes econômicas para oferecer maior quantidade de serviços de saúde. A menor produção em saúde per capita dos municípios da Região Metropolitana, quando comparada com as demais macrorregiões, decorre potencialmente da insuficiência da rede de atendimento dos municípios metropolitanos; da expansão da rede de serviços dos municípios interioranos que, por conterem menor densidade populacional, possuem menores dificuldades em relação ao dimensionamento da oferta de serviços de saúde, e da menor complexidade dos procedimentos ofertados pelos municípios interioranos. Por outro lado, é importante observar que o desvio-padrão é maior no Sertão $(28,56)$, seguido por Zona da Mata (19,94), Agreste $(13,75)$ e Região Metropolitana (10,02), ou seja, os sistemas municipais da Região Metropolitana são mais homogêneos.

A despesa corrente em saúde per capita apresenta comportamento diferente dentre os municípios das macrorregiões. A média per capita demonstra que os municípios da macrorregião Metropolitana possuem o maior valor médio de $\mathrm{R} \$ 354,32$, enquanto no Agreste os municípios apresentaram a menor média no valor de $\mathrm{R} \$ 313,28$, ou seja, os municípios da macrorregião Metropolitana apresentaram um gasto médio 13,10\% superior ao do Agreste. É importante notar que os municípios da macrorregião Metropolitana têm o maior gasto médio e possuem a menor produção média.

Tabela 2 - Estatísticas descritivas da produção em saúde e da despesa corrente per capita dos municípios pernambucanos por macrorregião, em $\mathrm{R} \$ * 2011$ a 2015

\begin{tabular}{l|rr|rr}
\hline \multirow{2}{*}{ Macrorregiões** } & \multicolumn{2}{|c|}{$\begin{array}{c}\text { Produção em } \\
\text { Saúde per capita }\end{array}$} & \multicolumn{2}{c}{$\begin{array}{c}\text { Despesa Corrente } \\
\text { per capita }\end{array}$} \\
\cline { 2 - 5 } & Média & $\begin{array}{c}\text { Desvio- } \\
\text { Padrão }\end{array}$ & Media & $\begin{array}{c}\text { Desvio- } \\
\text { Padrão }\end{array}$ \\
\hline RM & 20,43 & 10,02 & 354,32 & 190,34 \\
ZM & 26,89 & 19,94 & 325,03 & 81,55 \\
AG & 26,19 & 13,75 & 313,18 & 313,18 \\
ST & 29,43 & 28,56 & 342,38 & 95,34 \\
\hline
\end{tabular}

Nota: *RM: Região Metropolitana; ZM: Zona da Mata; AG: Agreste; ST: Sertão.

** Os valores monetários foram deflacionados a preços de 2011 pelo INPC/IBGE.

A Tabela 3 apresenta as estatísticas descritivas das variáveis financeiras e de controle relacionadas aos gastos com pessoal e investimento, ao financiamento das despesas em saúde pelo SUS e pelos recursos de impostos, a população e quantidade de médicos para cada mil habitantes dos municípios pernambucanos 
por macrorregiões. O perfil dos municípios, em relação aos aspectos financeiros e das variáveis de controle, assume também características bastante diferentes, já que de modo geral as variáveis apresentaram desviospadrões elevados na maioria das variáveis.

O tamanho populacional é bastante diferente entre os municípios das quatro macrorregiões, uma vez que a média e o desvio-padrão são grandes, ou seja, os municípios diferem em tamanho tanto entre as macrorregiões quanto internamente em cada uma delas. Em relação ao envelhecimento, o Agreste possui o maior índice de envelhecimento, que é de 42,32, seguido do Sertão com 36,70, Região Metropolitana com 36,50, e por último, a Zona da Mata com 33,65. Esses resultados evidenciam que os municípios pernambucanos ainda possuem uma população jovem em comparação com o cenário nacional, cuja última média apurada foi de 44,80 (Closs \& Schwanke, 2012).

A quantidade de médicos a cada mil habitantes é diferente entre os municípios de cada macrorregião. $\mathrm{Na}$ Região Metropolitana, os municípios têm o melhor indicador, com 0,58 médicos a cada mil habitantes, enquanto no Agreste os municípios que possuem o pior indicador contam com apenas 0,32 médicos a cada mil habitantes. No Sertão e na Zona da Mata os municípios possuem indicadores bem próximos ao obtido no Agreste, com 0,36 e 0,38 médicos a cada mil habitantes, respectivamente.

A proporção dos gastos em saúde na rubrica de pessoal nos municípios da região Metropolitana é 2,66\% superior a do Sertão (as regiões contam com 60,97\% e 58,31\%, respectivamente). Os municípios do Agreste apresentam maior percentual médio, com 62,19\%, enquanto os municípios do Sertão possuem o menor, com $58,31 \%$ dos gastos com pessoal. É importante notar que os percentuais médios obtidos por macrorregião, se analisados separadamente, sugerem dificuldades para que os gestores cumpram o limite de gasto com pessoal estabelecido pela LRF (Lei Complementar $n^{\circ} 101,2000$ ) de $54 \%$ para o poder executivo da Receita Corrente Líquida, fato que remete à necessidade de manter o gasto com pessoal proporcionalmente abaixo do limite em outras áreas, a fim de compensar o excedente do setor de saúde.

Nos gastos com investimento, os municípios do Sertão são maiores, com média de 5,83\%, enquanto na região Metropolitana, os municípios investem em média apenas 2,98\%, sendo os menores.

Já em relação às fontes de financiamento do SUS, a maior diferença ocorre entre os municípios das macrorregiões Agreste (49,29\%) e Sertão (46,97\%), embora seja de baixa intensidade, com apenas 2,32\%. Logo, a associação dos resultados obtidos nas variáveis "gasto pessoal" e "recurso SUS/despesa total" evidenciam que os recursos transferidos pelo SUS não são suficientes para o cumprimento das obrigações de pessoal, sendo necessária a utilização de recursos próprios resultantes de impostos.

A aplicação de recursos resultantes de impostos de acordo com a EC 29 em média é bastante superior ao limite mínimo estabelecido de $15 \%$ nos municípios das quatro macrorregiões. A maior aplicação média foi observada nos municípios do Agreste, com 20,59\%, e o menor foi nos municípios da macrorregião Metropolitana, com 18,61\%, ou seja, em razão do limite mínimo constitucional ser de $15 \%$, os municípios parecem não ter dificuldades para alcançar o cumprimento do gasto mínimo com recursos de impostos. 
Tabela 3 - Estatísticas Descritivas das Variáveis Financeiras e de Controle por Macrorregião, em R\$. 2011 a 2015.

\begin{tabular}{l|r|r|r|r}
\hline \multirow{2}{*}{ *Variável / Macrorregiões } & \multicolumn{1}{c|}{ RM } & \multicolumn{1}{c|}{ ZM } & \multicolumn{1}{c|}{ AG } & \multicolumn{1}{c}{$\mathrm{ST}$} \\
\cline { 2 - 5 } & $\begin{array}{r}\text { Média/ } \\
\text { Desvio- } \\
\text { Padrão }\end{array}$ & $\begin{array}{c}\text { Média/ } \\
\text { Desvio- } \\
\text { Padrão }\end{array}$ & $\begin{array}{c}\text { Média/ } \\
\text { Desvio- } \\
\text { Padrão }\end{array}$ & $\begin{array}{c}\text { Média/ } \\
\text { Desvio- } \\
\text { Padrão }\end{array}$ \\
\hline População (mil) & 273.177 & 31.450 & 32.422 & 29.353 \\
População com idade superior a 60 anos & $(405.58)$ & $(23.731)$ & $(42.535)$ & $(42.786)$ \\
& 28.481 & 2.974 & 3.556 & 2.831 \\
**Indice de envelhecimento & $(47.433)$ & $(2.392)$ & $(4.042)$ & $(3.031)$ \\
& 36,50 & 33,65 & 42,32 & 36,70 \\
Médico por mil habitantes capita & $(9,29)$ & $(7,06)$ & $(9,23)$ & $(10,46)$ \\
& 0,58 & 0,38 & 0,32 & 0,36 \\
Gasto pessoal (\%) & $(0,31)$ & $(0,21)$ & $(0,18)$ & $(0,22)$ \\
Gasto investimento (\%) & 63,83 & 60,97 & 62,19 & 58,31 \\
& $(10,28)$ & $(11,30)$ & $(9,81)$ & $(10,63)$ \\
Recurso SUS/despesa total (\%) & 2,98 & 3,72 & 5,03 & 5,83 \\
Recurso imposto/despesa total (\%) & $(2,52)$ & $(3,99)$ & $(4,65)$ & $(5,46)$ \\
& 45,86 & 48,08 & 48,29 & 46,97 \\
& $(16,65)$ & $(10,59)$ & $(9,85)$ & $(11,36)$ \\
& 18,61 & 19,74 & 20,59 & 20,39 \\
& $(3,98)$ & $(3,83)$ & $(4,29)$ & $(4,66)$ \\
\hline
\end{tabular}

Nota: Desvio-padrão entre parênteses; *RM: Região Metropolitana; ZM: Zona da Mata; AG: Agreste; ST: Sertão. ${ }^{* *}$ Índice de envelhecimento medido pela razão entre a população com 60 e mais anos e a população menor de 15 anos (Campos \& Gonçalves, 2018).

\subsection{Resultados Inferenciais}

A primeira etapa das estatísticas inferenciais consistiu em apurar a eficiência dos sistemas municipais de saúde por meio do modelo apresentado na equação 3. O modelo mensura a eficácia com base nos recursos financeiros e físicos utilizados na produção dos serviços de saúde, cujos resultados das estimações estão apresentados na Tabela 4.

$\mathrm{Na}$ Tabela 4 pode-se observar que os coeficientes estimados apresentaram significância estatística nas variáveis independentes ao nível de 5\%, o que evidencia a importância dos fatores de produção (mão-deobra, materiais e infraestrutura física) na produção dos serviços de saúde dos municípios. A despesa corrente demonstrou elasticidade (impacto que a alteração da variável explicativa produz na variável dependente) de $80,4 \%$ em relação à produção dos serviços de saúde, ou seja, o aumento de $1 \%$ na despesa corrente aumenta a produção em saúde em $0,804 \%$, enquanto a variável de estrutura ambulatorial e hospitalar ("Estrutura") apresentou elasticidade de 6,1\%. Assim, os coeficientes confirmam as indicações teóricas e práticas de que a produção dos serviços de saúde depende em maior parte dos fatores de produção relacionados aos recursos humanos, materiais e de serviços. 
Tabela 4 - Estimação do Modelo de Produção de Saúde dos Municípios de Pernambuco. 2001 a 2015.

\begin{tabular}{c|cccc}
\hline Variáveis & Coef. & $\begin{array}{c}\text { Erro } \\
\text { Padrão }\end{array}$ & Z & $\begin{array}{c}\text { Valor } \\
-\mathrm{p}\end{array}$ \\
\hline Despesa corrente $(\ln )$ & 0,804 & 0,035 & 22,94 & 0,000 \\
Estrutura $(\ln )$ & 0,061 & 0,026 & 2,32 & 0,020 \\
Constante & 1,342 & 0,687 & 1,95 & 0,051 \\
\hline
\end{tabular}

Log likelilhood $=1.135,318$.

O passo seguinte foi estimar o indicador de eficiência pelo parâmetro •it do modelo 3, que mensura a eficiência da produção dos serviços de saúde dos municípios pernambucanos, sendo a eficiência compreendida como a capacidade de produzir mais com a mesma quantidade de recursos, ou a produção da mesma quantidade com a menor utilização de recursos. $\mathrm{O}$ indicador possui variação de 0 (ineficiência total) a 1 (eficiência total). Nenhum município alcançou o indicador máximo de um e o mínimo de zero. Os dados obtidos foram segregados e apresentados na Tabela 5 por macrorregião do estado. Os municípios da macrorregião que apresentaram maior média foram os do Agreste, com 0,379, e os que apresentaram a menor média foram os do Sertão, com 0,361. Esse resultado não era esperado, uma vez que os municípios da Região Metropolitana apresentam maior escala na produção dos serviços. Uma outra explicação é a potencial maior complexidade dos serviços oferecidos pelos municípios metropolitanos, que possuem maiores custos o que, consequentemente, prejudica a mensuração de eficiência.

Tabela 5 - Indicador de Eficiência da Produção em

Saúde por Macrorregião de Pernambuco. 2011 a 2015

\begin{tabular}{l|rrrr}
\hline Macrorregiões* & Média & $\begin{array}{c}\text { Desvio- } \\
\text { Padrão }\end{array}$ & Mín. & Máx. \\
\hline RM & 0,372 & 0,092 & 0,220 & 0,552 \\
ZM & 0,371 & 0,095 & 0,184 & 0,694 \\
AG & 0,379 & 0,086 & 0,215 & 0,760 \\
ST & 0,361 & 0,100 & 0,133 & 0,683 \\
\hline
\end{tabular}

* RM: Região Metropolitana; ZM: Zona da Mata; AG: Agreste; ST: Sertão.

Com o propósito de facilitar a visualização da eficiência dos municípios ao longo do território pernambucano, um mapa temático foi elaborado com o indicador de eficiência apurado. A Figura 1 apresenta o mapa temático dos indicadores médios apurados para todos os municípios pernambucanos segundo faixas do indicador de eficiência (classe 1: Até 0,1504; classe 2: 0,1504 a 0,3007; classe 3: 0,3007 a 0,4511; classe 4: 0,4511 a 0,6014; e classe 5: 0,6014 a 0,7518). Na classe 1, de municípios com menor eficiência, obteve somente um município; as classes 2, 3, 4 e 5 tiveram 38, 116, 23 e 5 municípios, respectivamente.

Os maiores índices foram observados nos seguintes municípios: Riacho das Almas (Agreste), com 0,7518, Quipapá (Zona da Mata), com 0,6842, Manari (Sertão), com 0,6724, Ribeirão (Zona da Mata), com 0,6398, e Santa Cruz da Baixa Verde (Sertão), com 0,6162. Já os municípios que tiveram os menores índices de eficiência foram: Itacuruba (Sertão), com 14,44, São Benedito do Sul (Zona da Mata), com 0,1970, Joaquim Nabuco (Zona da Mata), com 0,2046, e Carnaubeira da Penha (Sertão), com 20,47. A análise do mapa ainda sugere que os municípios com menores indicadores de eficiência estão em maior frequência localizados na macrorregião do Sertão pernambucano.

É importante observar que os cinco maiores indicadores foram observados em três macrorregiões diferentes (Agreste, Sertão e Zona da Mata) e os cinco menores indicadores foram observados em duas 
macrorregiões diferentes (Sertão e Zona da Mata). Isso sugere que melhores ou piores indicadores de eficiência não estão essencialmente relacionados à localização dos municípios nas macrorregiões do estado.

Figura 1. Mapa temático da Eficiência de Produção em

Serviços dos Municípios de Pernambuco. 2011 a 2015

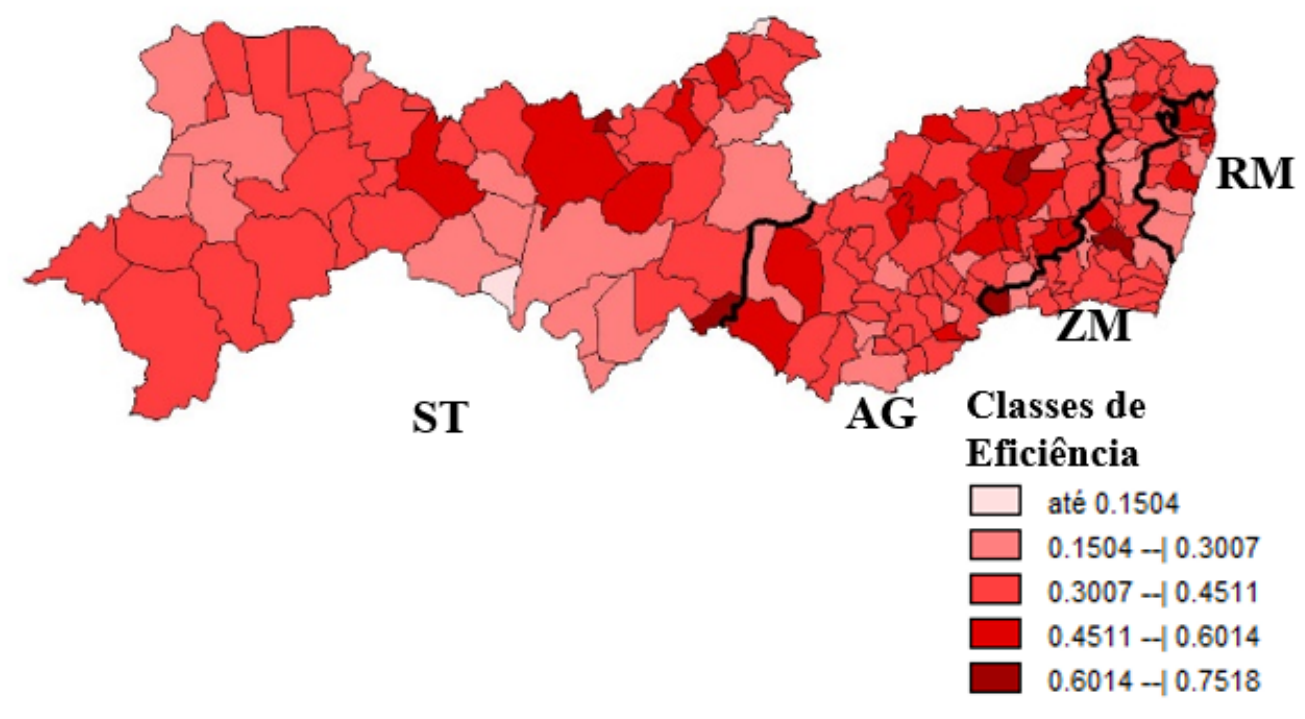

* RM: Região Metropolitana; ZM: Zona da Mata; AG: Agreste; ST: Sertão.

A segunda etapa das estatísticas inferenciais consistiu em estimar o modelo da equação 4 para mensurar os efeitos das variáveis financeiras e de controle na eficiência da produção dos serviços de saúde dos municípios pernambucanos, conforme resultados apresentados na Tabela 6 a seguir:

Tabela 6 - Estimação da Regressão Múltipla com Erros Robustos da Eficiência de Saúde e as Variáveis Populacional e Financeiras. 2011 a 2015

\begin{tabular}{l|r|r|r}
\hline \multicolumn{1}{c|}{ Variáveis } & Coef. & $\begin{array}{c}\text { E-Padrão } \\
\text { Robusto }\end{array}$ & Estatís-tica t \\
\hline População com idade superior a 60 anos (ln) & $-0,16228$ & 0,00484 & $-32,83^{* * *}$ \\
Médicos por mil habitantes (ln) & 0,00135 & 0,00068 & $1,99^{* *}$ \\
Gasto com pessoal em saúde (\%) & 0,00009 & 0,00003 & $2,79 * * *$ \\
Gasto com investimento em saúde (\%) & 0,00015 & 0,00005 & $3,27 * * *$ \\
Despesa em saúde financiada com recursos do SUS (\%) & 0,00007 & 0,00003 & $2,39 * *$ \\
Despesa em saúde financiada com recursos de impostos (\%) & 0,00017 & 0,00007 & $2,31^{* *}$ \\
$\quad$ Constante & 0,19311 & 0,00976 & $19,79 * * *$ \\
\hline
\end{tabular}

${ }^{* * *}$ Coeficiente estatisticamente significativo ao nível de $1 \%,{ }^{* *} 5 \% \mathrm{e}^{*} 10 \%$.

A estimação da regressão evidenciou que as variáveis financeiras foram estatisticamente significativas ao nível de 5\%. Além disso, apenas a variável “população com idade superior a 60 anos” influencia negativamente na eficiência dos serviços de saúde dos municípios, enquanto a quantidade de médicos a cada mil habitantes, o gasto com pessoal em saúde, o gasto com investimento em saúde, a despesa em saúde financiada com recursos do SUS e a despesa em saúde financiada com recursos de impostos influenciam positivamente na eficiência.

É importante frisar que modelos alterativos foram estimados com a inclusão individual das variáveis explicativas econômicas de PIB e renda per capita com o propósito de obter o melhor modelo explicativo da eficiência de saúde dos governos locais pernambucanos. Entretanto, por ocorrência de multicolinearidade excessiva entre cada variável econômica e a variável população com idade superior a 60 anos (Variance 
Inflation Factor $>10$ ) e por apresentarem menor capacidade de ajuste, as variáveis referentes ao PIB e à renda per capita não foram não mantidas no modelo.

\section{DISCUSSÕES}

As diferenças de produção e despesa corrente média per capita observadas entre os municípios das macrorregiões pelas estatísticas descritivas demonstram que a normatização e os critérios utilizados para realização das transferências intergovernamentais não têm sido suficientes para assegurar a uniformidade dos sistemas de saúde dos governos locais. A diferença média per capita da produção evidencia que o acesso é 44\% superior nos municípios do Sertão em comparação com os municípios da Região Metropolitana.

Os dados de produção apresentados na Tabela 2 sugerem que os municípios da Região Metropolitana não possuem estrutura física capaz de atender as demandas da população, além de reforçar o argumento de que os municípios mais pobres e localizados longe dos grandes centros são capazes de possuir estruturas operacionais de sistemas de saúde, embora possuam menor eficiência (Arretche, 2004; Fleuy et. al., 2014).

A eficiência dos sistemas de saúde dos municípios pernambucanos apresentou baixo indicador nas macrorregiões, em média atingiu apenas 0,37 , ou seja, os municípios alcançaram apenas $37 \%$ da eficiência dos serviços de saúde possível. Os cinco municípios que apresentaram maiores indicadores estão localizados em macrorregiões distintas. Esse resultado reforça a possibilidade de alcançar melhores índices em todas as macrorregiões do estado, independente das condições sociais e econômicas. Aspectos relacionados à capacidade de gestão podem ser fatores determinantes do alcance de melhor eficiência (Fleury et al., 2014).

Já quanto às varáveis financeiras e de controle objeto do estudo, os resultados da regressão de eficiência dos sistemas de saúde apresentados na Tabela 6 evidenciam que a população com idade superior a 60 anos é a variável que apresenta maior intensidade na influência da eficiência. Esse resultado era esperado, já que a maior quantidade de idosos favorece a menor eficiência, em razão de necessitarem de cuidados mais complexos e de maior custo. A variável de controle da qualidade, "médicos a cada mil habitantes", foi significativa ao nível de $5 \%$. Esse resultado evidencia que a preocupação com a qualidade dos serviços pode contribuir para que haja efeitos positivos na eficiência da saúde dos municípios.

Em relação às variáveis financeiras, os municípios apresentam proporção de gasto com pessoal no setor de saúde em quantidade superior ao limite máximo definido de $54 \%$ para poder executivo pela LRF. Os municípios da macrorregião Metropolitana possuíram a maior proporção, superando em 9,83\% o limite estabelecido pela LRF, algo que resulta em dificuldades para as demais áreas de atuação dos municípios, porque o gasto com pessoal excedente no setor saúde acaba tendo que ser compensado nos outros, visto que o limite máximo de gasto com pessoal é para o poder executivo como um todo e não para o setor de saúde especificamente (Luque \& Silva, 2004). Já os resultados inferenciais apresentados na Tabela 6 evidenciaram que o gasto com pessoal influencia positivamente a eficiência dos sistemas de saúde, visto que a mão-de-obra é o principal fator utilizado na produção dos serviços de saúde. Esse resultado refuta a ideia de que os gastos com pessoal são nocivos à eficiência da administração pública municipal, porque a área da saúde necessita realizar maiores gastos com pessoal para manutenção de mão-de-obra especializada. Ou seja, níveis de gasto com pessoal superiores ao limite legal não necessariamente implica em menor eficiência (Luque \& Silva, 2004).

Em relação à proporção dos gastos com investimento, os resultados obtidos demonstram que os municípios possuem baixa capacidade de realizar investimentos e que existem diferenças entre os municípios das macrorregiões. No Sertão, por exemplo, os gastos com investimentos dos municípios representam 5,83\% do gasto total em saúde, enquanto na macrorregião Metropolitana alcançam apenas 2,98\%. Além disso, as estatísticas inferenciais apresentadas na Tabela 6 evidenciaram que o gasto em investimento no setor de saúde influencia na eficiência da produção dos serviços de saúde. Assim, esses resultados demonstram a baixa capacidade que os municípios possuem para aperfeiçoar a estrutura física e adotar novas tecnologias para o aprimoramento da eficiência (Santolin et al., 2009; Gerigk et al., 2010). 
O financiamento do gasto em saúde por meio das transferências intergovernamentais do SUS teve percentual médio nos municípios das macrorregióes Metropolitana e Agreste de 45,86\% e 48,29\%, respectivamente. O desvio-padrão da participação do SUS no financiamento entre os municípios demonstram que a Região Metropolitana é a que possui maior desigualdade. A estimação inferencial revelou que a participação dos recursos influencia positivamente a eficiência, sinalizando que as normas de aplicação dos recursos do SUS podem provocar maior eficiência da produção dos serviços de saúde (Melamed \& Costa, 2003; Scatena et al., 2009).

A aplicação dos recursos de impostos em saúde nos municípios apresenta percentual médio bastante superior ao limite mínimo de $15 \%$ estabelecido pela Emenda Constitucional $n^{\circ} 29$ nas quatro macrorregiões, conforme resultados observados pela média da variável de participação dos impostos no gasto total apresentada na Tabela 3. Os gastos mínimos em saúde pelos municípios parecem ser algo já institucionalizado, visto que a ocorrência de aplicação inferior durante o período de estudo foi de apenas 16 vezes dentre 920 observaçóes (184 municípios em 5 anos). Os resultados apurados no modelo inferencial apresentados na Tabela 6 demonstram que essa aplicação de recursos de impostos influencia positivamente na eficiência. Assim, a norma legal parece estar alcançando o objetivo de assegurar recursos mínimos ao setor de saúde nos municípios e contribui com a eficiência dos gastos.

\section{CONCLUSÃO}

Os municípios pernambucanos apresentam características desiguais tanto em relação aos aspectos de oferta dos serviços de saúde, quanto ao financiamento e a composição dos gastos. A desigualdade também é revelada na eficiência dos sistemas locais de saúde. A região do Agreste apresentou a maior média de eficiência, com 0,379, seguida pela Região Metropolitana, com 0,372, Zona da Mata, com 0,371 e por último, o Sertão, com 0,361. Embora os menores níveis de eficiência estejam presentes na macrorregião do Sertão, que está localizada no extremo interior do estado, caracterizada por sofrer com escassez hídrica e alta incidência de calor, nota-se que ela também apresenta municípios que alcançaram altos níveis de eficiência, evidenciando que as diferenças de eficiência estão relacionadas aos fatores internos dos municípios e não a sua localização nas macrorregiões. Por outro lado, a complexidade dos serviços oferecidos pode ser uma potencial explicação para o menor nível de eficiência dos municípios metropolitanos.

Em síntese, o estudo conclui que as variáveis de financiamento e de composição dos gastos apresentaram influência positiva na eficiência. Os gastos com investimentos, embora pouco expressivos em relação ao gasto total em saúde, têm influência positiva na eficiência. Ou seja, gastos com o aprimoramento da estrutura física e tecnológica são importantes para melhoria da eficiência. O gasto com pessoal também influencia positivamente na eficiência, algo que refuta o argumento de que gastos com pessoal acima do limite legal sejam prejudiciais à eficiência dos serviços de saúde. Ou seja, no setor de saúde o gasto com pessoal não necessariamente precisa ser inferior ao limite máximo de $54 \%$ de suas receitas para que seja eficiente.

O financiamento pelo SUS influencia positivamente na eficiência dos sistemas de saúde dos municípios. Isso sugere que o controle normativo das transferências do SUS provoca maior eficiência no gasto público em saúde dos municípios. Em média, a aplicação dos recursos de impostos em ações e serviços de saúde é realizada acima do limite mínimo legal e possui influência positiva na eficiência dos sistemas de saúde dos municípios.

A variável de controle "população com idade superior a 60 anos" influencia negativamente a eficiência, algo que confirma as indicações teóricas, porque esse público requer serviços de saúde mais complexos e onerosos. Já a variável "médicos a cada mil habitantes" foi estatisticamente significativa ao nível de $5 \%$ em relação à eficiência.

As principais limitações do estudo estão relacionadas principalmente à impossibilidade de segregar os procedimentos de saúde entre as abordagens preventivas e curativas, à dificuldade de contemplar a migração de pessoas que buscam atendimento médico nos diferentes municípios, especialmente na região 
metropolitana, ao tratamento da análise descritiva por macrorregião, à fragilidade da base de dados do DATASUS, especialmente em relação aos atendimentos ambulatoriais e do PSF, à utilização de proxy para estrutura física e à dificuldade de considerar metodologicamente a diversidade e complexidade que os procedimentos de saúde podem ter efeitos sobre a eficiência dos sistemas. Portanto, essas limitações são estímulos para o desenvolvimento de futuras pesquisas.

\section{REFERENNCIAS}

Abrúcio, F. L. (2006). Para além da descentralização: os desafios da coordenação federativa no Brasil. Democracia, descentralização e desenvolvimento: Brasil e Espanha. Rio de Janeiro: Editora FGV, 77-125.

Achabal, D., Heineke, J., McIntyre, S. H. (1984). Issues and perspectives on retail productivity. Journal of Retailing, $60(3), 107-27$.

Afonso, A., St Aubyn, M. (2005). Non-parametric approaches to education and health efficiency in OECD countries. Journal of Applied Economics, 8(2), 227.

Afonso, A., St. Aubyn, M. (2011). Assessing health efficiency across countries with a two-step and bootstrap analysis. Applied Economics Letters, 18(15), 1427-1430.

Afonso, J. R. Araújo, E. A. (2000) A capacidade de gastos dos municípios brasileiros: arrecadação própria e receita disponivel. Os municipios e as eleições de 2000. São Paulo: Konrad Adenauer Stiftung, 35-56.

Aigner, D., Lovell, C. K., Schmidt, P. (1977). Formulation and estimation of stochastic frontier production function models. Journal of econometrics, 6(1), 21-37.

Allin, S., Grignon, M., Wang, L. (2016). The determinants of efficiency in the Canadian health care system. Health Economics, Policy and Law, 11(01), 39-65.

Amado, C. A. F., Santos, S. P. (2009). Challenges for performance assessment and improvement in primary health care: the case of the Portuguese health centres. Health Policy, 91(1), 43-56.

Arretche, M. (2003). Financiamento federal e gestão local de políticas sociais: o difícil equilíbrio entre regulação, responsabilidade e autonomia. Ciência \& Saúde Coletiva, 8(2), 331-345.

Arretche, M. (2004). Federalismo e políticas sociais no Brasil: problemas de coordenação e autonomia. São Paulo em perspectiva, 18(2), 17-26.

Asmild, M., Paradi, J. C., Reese, D. N., Tam, F. (2007). Measuring overall efficiency and effectiveness using DEA. European Journal of Operational Research, 178(1), 305-321.

Barton, A. (2009). The use and abuse of accounting in the public sector financial management reform program in Australia. Abacus, 45(2), 221-248.

Battese, G. E., Coelli, T.J. (1992). Frontier production functions, technical efficiency and panel data: with application to paddy farmers in India. In International applications of productivity and efficiency analysis (149-165). Springer Netherlands.

Bird, R. M., Freund, C. L., Wallich, C. I. (1995). Decentralizing fiscal systems in transition economies. Finance and Development, 32(3), 1-31.

Braga, G. B., Ferreira, M. A. M., Braga, B. B. (2015). A Eficiência da Atenção Primária à Saúde: Avaliando Discrepâncias. Administração Pública e Gestão Social, 7(2), 100-107.

Bresser-Pereira, L. C. (2000). A reforma gerencial do Estado de 1995. Revista de administração pública, 34(4), 7-26.

Bresser-Pereira, L. C. (2009). Construindo o Estado republicano: democracia e reforma da gestão pública. Rio de Janeiro: Fgv.

Buchanan, J. M., Tullock, G. (1962). The calculus of consent (V. 3). Ann Arbor: University of Michigan Press.

Campos, A. C. V., Gonçalves, L. H. T. (2018). Perfil demográfico do envelhecimento nos municípios do estado do Pará, Brasil. Revista Brasileira de Enfermagem, 71(1), 591-598. 
Carvalho, A. M. (2002). Estado, descentralização e sustentabilidade dos governos locais no Brasil. Economía Sociedad y Territorio.

Carrillo, M., Jorge, J. M. (2017). DEA-like efficiency ranking of regional health systems in Spain. Social Indicators Research, 133(3), 1133-1149.

Cetin, V. R., Bahce, S. (2016). Measuring the efficiency of health systems of OECD countries by data envelopment analysis. Applied Economics, 48(37), 3497-3507.

Closs, V.E., Schwanke, C. H. A. (2012). A evolução do índice de envelhecimento no Brasil, nas suas regiões e unidades federativas no período de 1970 a 2010. Revista brasileira de geriatria e gerontologia, 15(3), 443-458.

Costa, C. C. M., Ferreira, M. A. M., Braga, M. J., Abrantes, L. A. (2015). Fatores associados à eficiência na alocação de recursos públicos à luz do modelo de regressão quantílica. Revista de Administração Pública, 49(5), 1319-1347.

Dain, S. (2007). Os vários mundos do financiamento da Saúde no Brasil: uma tentativa de integração. Ciência \& saúde coletiva, 1(1), 1851-1864.

Downs, A. (1957) An economic theory of democracy. Nova York: Harper and Row.

Faria, T. L. M., Nascimento, D. M., Farias, M. C., Filho, Nunes, S. F. (2017). A Política Nacional de Urgência e Emergência sob a Coordenação Federativa em Municípios Paraenses. Saúde e Sociedade, 26(1), 726-737.

Farrell, M. J. (1957). The measurement of productive efficiency. Journal of the Royal Statistical Society. Series A (General), 120(3), 253-290.

Ferrera, J. M. C., Cebada, E. C., Zamorano, L. R. M. (2014). The effect of quality and socio-demographic variables on efficiency measures in primary health care. The European journal of health economics, 15(3), 289-302.

Ferreira, M. P., Pitta, M. T. (2008). Avaliação da eficiência técnica na utilização dos recursos do sistema único. São Paulo em Perspectiva, 22(2), 55-71.

Fioravante, D. G., Pinheiro, M. M. S., Vieira, R. D. S. (2006). Lei de responsabilidade fiscal e finanças públicas municipais: impactos sobre despesas com pessoal e endividamento. Texto para Discussão no 1223, Brasília: Ipea.

Fleury, S. (2009). Financiamento e equidade em saúde-por um novo contrato social/Financing and equity in healthfor a new social contract. Revista SER Social, 11(25), 16-29.

Fleury, S., Ouverney, A. M., Möller, R. C., Kronemberger, T. S., Zani, F. B. (2014). Organização local da atenção à saúde no SUS: a dimensão assistencial. In S. Fleury (Org.), Democracia e Inovação na Gestão Social da Saúde (385-413). Rio de Janeiro: Editora Fiocruz.

Fonchamnyo, D. C., Sama, M. C. (2016). Determinants of public spending efficiency in education and health: evidence from selected CEMAC countries. Journal of Economics and Finance, 40(1), 199-210.

Fonseca, P. C., Ferreira, M. A. M. (2009). Investigação dos níveis de eficiência na utilização de recursos no setor de saúde: uma análise das microrregiões de Minas Gerais. Saúde e Sociedade, 18(2), 199-213.

Fontoura, R. T., Mayer, C. N. (2006). Uma breve reflexão sobre a integralidade. Revista Brasileira de Enfermagem, 59(4), 532-536.

Gerigk, W., Clemente, A., Taffarel, M. (2010). O impacto da lei de responsabilidade fiscal sobre a gestão financeira dos pequenos municípios: o caso do Paraná. Revista de Educação e Pesquisa em Contabilidade, 4(3), 44-69.

Greene, W. (2004). Distinguishing between heterogeneity and inefficiency: stochastic frontier analysis of the World Health Organization's panel data on national health care systems. Health economics, 13(10), 959-980.

Greene, W. (2010) A stochastic frontier model with correction for sample selection. Journal of Productivity Analysis, $34(1), 15-24$.

Grossman, M. (1972). The demand for health: a theoretical and empirical investigation. NBER Books.

Hadad, S., Hadad, Y., Simon-Tuval, T. (2013). Determinants of healthcare system's efficiency in OECD countries. The European Journal of Health Economics, 14(2), 253-265.

Herwartz, H., Schley, K. (2018). Improving health care service provision by adapting to regional diversity: An efficiency analysis for the case of Germany. Health Policy, 122(3), 293-300.

Hollingsworth, B. (2008). The measurement of efficiency and productivity of health care delivery. Health economics, 17(10), 1107-1128. 
Hollingsworth, B., Wildman, J. (2003). The efficiency of health production: re - estimating the WHO panel data using parametric and non - parametric approaches to provide additional information. Health Economics, 12(6), 493-504.

IBGE. Instituto Brasileiro de Geografia e Estatística. SIDRA - Sistema IBGE de Recuperação Automática. Recuperado, em Setembro, de: http://www.sidra.ibge.gov.br.

Ibrahim, M. D., Daneshvar, S., Hocaoğlu, M. B., Oluseye, O. W. G. (2018). An Estimation of the Efficiency and Productivity of Healthcare Systems in Sub-Saharan Africa: Health-Centred Millennium Development GoalBased Evidence. Social Indicators Research, 1-19.

Keh, H. T., Chu, S., Xu, J. (2006). Efficiency, effectiveness and productivity of marketing in services. European Journal of Operational Research, 170(1), 265-276.

Kis-Katos, K., Sjahrir, B. S. (2017). The impact of fiscal and political decentralization on local public investment in Indonesia. Journal of Comparative Economics, 45(2), 344-365.

Kumbhakar, S. C. (2010). Efficiency and productivity of world health systems: where does your country stand? Applied Economics, 42(13), 1641-1659.

Kumbhakar, S. C., Lovell, C. K. (2000). Stochastic frontier analysis. Cambridge university press.

Luque, C. A., Silva, V. M. (2004). A lei de responsabilidade na gestão fiscal: combatendo falhas de governo à brasileira. Revista de Economia Política, 24(3), 404-421.

Macedo, J. D. J., Corbari, E. C. (2009). Efeitos da lei de responsabilidade fiscal no endividamento dos municípios brasileiros: uma análise de dados em painéis. Revista Contabilidade \& Finanças-USP, 20(51), 44-60.

Marinho, A. (1998) Estudo de eficiência em hospitais públicos e privados com a elaboração de rankings. Revista de Administração Pública, 32(6), 145-158.

Marinho, A. (2003). Avaliação da eficiência técnica nos serviços de saúde nos municípios do Estado do Rio de Janeiro. Revista brasileira de economia, 57(3), 515-534.

Marinho, A., Façanha, L. O. (2000). Programas sociais: Efetividade, eficiência e eficácia como dimensöes operacionais. Brasília: DF, IPEA.

Mazon, L. M., Mascarenhas, L. P. G., Dallabrida, V. R. (2015). Eficiência dos gastos públicos em saúde: desafio para municípios de Santa Catarina, Brasil. Saúde e Sociedade, 24(1), 23-33.

Medeiros, K. R. D., Albuquerque, P. C. D., Tavares, R. A. W., Souza, W.V.D. (2017). Lei de Responsabilidade Fiscal e as despesas com pessoal da saúde: uma análise da condição dos municípios brasileiros no período de 2004 a 2009. Ciência \& Saúde Coletiva, 22(1), 1759-1769.

Meeusen, W., \& Van Den Broeck, J. (1977). Efficiency estimation from Cobb-Douglas production functions with composed error. International Economic Review, 18(2), 435-444.

Melamed, C., \& Costa, N. D. R. (2003). Inovações no financiamento federal à Atenção Básica. Ciência \& Saúde Coletiva, 8(2), 393-401.

Oates, W. E. (1999). An essay on fiscal federalism. Journal of economic literature, 37(3), 1120-1149.

Ogloblin, C. (2011). Health care efficiency across countries: a stochastic frontier analysis. Applied Econometrics and International Development, 11(1), 5-14.

Ozcan, Y. A. (2008). Health care benchmarking and performance evaluation. An assessment using data envelopment analysis $(D E A), 4$.

Ozcan, Y. A. (2009). Quantitative methods in health care management: techniques and applications (V. 4). John Wiley \& Sons.

Pacheco, M. J. J., Abrantes, L. A., Zuccolotto, R., \& de Almeida Luquini, R. (2017). Emendas Constitucionais e Descentralização Fiscal: Evolução e Interferências na Autonomia Financeira dos Municípios. Desenvolvimento em Questão, 16(42), 180-208.

Paim, J., Travassos, C., Almeida, C., Bahia, L., \& Macinko, J. (2011). The Brazilian health system: history, advances, and challenges. The Lancet, 377(9779), 1778-1797. 
Park, J. S., Fowler, K. L., \& Giebel, S. A. (2011). Measuring hospital operating efficiencies for strategic decisions. International Journal of Business and Social Science, 2(13).

Pinto, L. F., Soranz, D., Scardua, M. T., \& Silva, I. D. M. (2017). A regulação municipal ambulatorial de serviços do Sistema Único de Saúde no Rio de Janeiro: avanços, limites e desafios. Ciência \& Saúde Coletiva, 22(1), 1257-1267.

Portulhak, H., Raffaelli, S. C. D., \& Scarpin, J.E. (2018). A Eficiência da Aplicação de Recursos Voltada à Saúde Pública nos Municípios Brasileiros. Revista Contabilidade, Gestão e Governança, 21(1), 21-39.

Puig-Junoy, J. (1998). Measuring health production performance in the OECD. Applied Economics Letters, 5(4), 255-259.

Queiroz, M. D. F. M., Silva, J. L. M., Figueiredo, J. S., \& Vale, F. F. R. (2013). Eficiência no gasto público com saúde: uma análise nos municípios do Rio Grande do Norte. Revista Econômica do Nordeste, 44(3), 761-776.

Rodden, J. (2003). Federalism and bailouts in Brazil. Fiscal decentralization and the challenge of hard budget constraints, $213-48$.

Sacramento, A. R. S. (2005). Contribuições da Lei de Responsabilidade Fiscal para o avanço da accountability no Brasil. Cadernos Gestão Pública e Cidadania, 10(47), 20-47.

Santolin, R., Jayme, F. G., Jr., \& Reis, J. C. D. (2009). Lei de Responsabilidade Fiscal e implicações na despesa de pessoal e de investimento nos municípios mineiros: um estudo com dados em painel dinâmico. Estudos Econômicos (São Paulo), 39(4), 895-923.

Santos, T. O., Pereira, L. P., \& Silveira, D. T. (2017). Implantação de sistemas informatizados na saúde: uma revisão sistemática. Revista Eletrônica de Comunicação, Informação \& Inovação em Saúde, 11(3), 1-11.

Santos, J. A., Neto, Mendes, Á. N., Pereira, A. C., \& Paranhos, L. R. (2017). Análise do financiamento e gasto do Sistema Único de Saúde dos municípios da região de saúde Rota dos Bandeirantes do estado de São Paulo, Brasil. Ciência \& Saúde Coletiva, 22(1), 1269-1280.

Scatena, J. H. G., Viana, A. L. D. Á., \& Tanaka, O. Y. (2009). Sustentabilidade financeira e econômica do gasto público em saúde no nível municipal: reflexões a partir de dados de municípios mato-grossenses. Cadernos de Saúde Pública, 25(11), 2433-2445.

Simão, J. B., \& Orellano, V. I. F. (2015). Um estudo sobre a distribuição das transferências para o setor de saúde no Brasil. Estudos Econômicos (São Paulo), 45(1), 33-63.

Souza, C. (2005). Federalismo, desenho constitucional e instituições federativas no Brasil pós-1988. Revista de sociologia e politica, 24(24), 105-122.

Varabyova, Y., \& Müller, J. M. (2016). The efficiency of health care production in OECD countries: A systematic review and meta-analysis of cross-country comparisons. Health Policy, 120(3), 252-263.

Varela, P. S. (2008). Financiamento e controladoria dos municípios paulistas no setor saúde: uma avaliação de eficiência. Tese de Doutorado, Faculdade de Economia, Administração e Contabilidade, Universidade de São Paulo (USP), São Paulo.

Varela, P. S., Martins, G. A., \& Fávero, L. P. L. (2012). Desempenho dos municípios paulistas: uma avaliação de eficiência da atenção básica à saúde. Revista de Administração, 47(4), 624-637.

Varela, P. S., Martins, G. A., Fávero, L.P. L. (2010) Production efficiency and financing of public health: an analysis of small municipalities in the state of São Paulo - Brazil. Health Care Management Science, 3(2), 112-123.

Wagner, G. (2006). Efeitos paradoxais da descentralização no Sistema Único de Saúde do Brasil. Democracia, descentralização e desenvolvimento: Brasil \& Espanha, 417.

World Bank (2016). Catalog sources World Development Indicators. Recuperado, em 10 de Maio de 2016, de: http:/ /data.worldbank.org/indicator/GC.TAX.TOTL.GD.ZS.

\section{BY-NC-ND}

